\title{
Behavioral and Antinociceptive Effects of Different Psychostimulant Drugs in Prenatally Methamphetamine-Exposed Rats
}

\author{
A. YAMAMOTOVÁ ${ }^{1}$, R. ŠLAMBEROVÁ ${ }^{1}$ \\ ${ }^{1}$ Department of Normal, Pathological and Clinical Physiology, Third Faculty of Medicine, Charles \\ University in Prague, Prague, Czech Republic
}

Received March 19, 2012

Accepted July 13, 2012

\begin{abstract}
Summary
Prenatal exposure to methamphetamine (METH) increases nociceptive sensitivity in adult rats. As the strong analgesics have high abuse potential and drugs of abuse are known to have analgesic properties, the aim was to study analgesic effect of different psychostimulants in control and prenatally METHexposed rats. Latencies of withdrawal reflexes of hind limbs and the tail on thermal nociceptive stimuli were repeatedly measured in 15-min intervals after the application of $5 \mathrm{mg} / \mathrm{kg} \mathrm{S.C.} \mathrm{of}$ amphetamine (AMPH), methamphetamine (METH), cocaine (COC), 3,4-methylenedioxymethamphetamine (MDMA) or morphine (MOR). In all groups, AMPH induced on hind limbs stronger analgesia than METH and MDMA whereas COC and MOR were practically without any effect. On the tail, effect of $A M P H$ did not differ from that of MOR. All psychostimulants increased defecation in comparison with MOR and in all groups the number of defecation boluses positively correlated with analgesia of the hind limbs. We did not confirm that prenatal exposure to METH makes adult rats more sensitive either to same drug or to other psychostimulants. The different analgesic potencies of psychostimulants and MOR at different body sites indicate the possible existence of a somatotopic organization of pain inhibition, which is controlled by different mechanisms.
\end{abstract}

\section{Key words}

Antinociception - Plantar test - Prenatal methamphetamine • Psychostimulant drugs • Morphine

\section{Corresponding author}

Anna Yamamotová, Charles University in Prague, Department of Normal, Pathological and Clinical Physiology, Ke Karlovu 4, 12000 Prague 2, Czech Republic. E-mail: yamamoto@lf3.cuni.cz

\section{Introduction}

In recent years an increasing number of works have been published concerning a common mechanism of reward and analgesic effects of addictive substances (Becerra et al. 2001, Borsook et al. 2007, Leknes and Tracey 2008). For example, it is well known that morphine (MOR) and amphetamine (AMPH) are acting analgesic agents and both of them produce a strong dependence. Results show that this is not just a random association, but that both systems share a common neurophysiological substrate (Franklin 1998). Analgesic and rewarding effects are mediated by similar receptors and similar sites of action. It involves dopaminergic neurons that are located in the ventral tegmental area (VTA) and project to various forebrain sites including the nucleus accumbens (NAc). Opioids cause the release of dopamine from these neurons through inhibition of GABAergic neurons (Johnson and North 1992, Koob 1992), whereas psychostimulant drugs increase extracellular dopamine directly.

Different psychostimulants increase noradrenalin and dopamine levels by means of different mechanisms, either by stimulating the release of mediators or inhibiting their reuptake. Cocaine primarily inhibits reuptake, whereas AMPH and its derivatives affect the release and reuptake. When comparing the effect of AMPH and methamphetamine (METH) it has been shown that AMPH is more potent than METH, but both have a similar pharmacological profile consisting in the fact that most affected is the release of noradrenalin, then dopamine and at least is influenced the release of serotonin (Rothman et al. 2001, Rothman and Baumann 2003). 
Two different substances such as AMPH and MOR operate as analgesics through a reward system in which mesolimbic dopaminergic pathways linking the ventral tegmentum to the ventral striatum play a key role. AMPH analgesia can be blocked by antagonists of D1 or D2 receptors or by lesions in VTA induced by 6hydroxydopamine application (Morgan and Franklin 1990, Morgan and Franklin 1991). It is highly probable that dopamine may play a role in the analgesic effects of other addictive substances.

Recently we have shown that prenatal exposure to METH has long-term impact on nociceptive sensitivity. In adulthood, METH-induced analgesia develops faster in prenatally METH exposed rats than in control animals, although absolute analgesic effect of the drug was in both groups similar (Yamamotová et al. 2011). Also adult offspring prenatally exposed to METH had higher basal levels of dopamine and show higher response to the challenge dose of METH, when compared to controls (Bubenikova-Valesova et al. 2009).

Although drugs of abuse are known to have analgesic properties, there exists no experimental study which would compare antinociceptive effect of different psychostimulant drugs in animals prenatally exposed to METH. Repeated administration of drug of abuse may induce either sensitization to the same drug or may increase sensitivity to another drug. Aim of the present study was to compare antinociceptive effect of AMPH, METH, cocaine (COC), 3,4-methylenedioxymethamphetamine (MDMA), and MOR and to assess whether increased sensitivity to pain observed in prenatally METH treated rats may be an indicator for the development of sensitization to similar or dissimilar drugs.

\section{Methods}

Nociception was tested during 85-90 postnatal day in three groups of male Wistar rats $(\mathrm{N}=120)$. The experimental group consisted of animals whose mothers were during entire pregnancy daily treated with METH $(5 \mathrm{mg} / \mathrm{kg}$; s.c.); in the saline group, mothers were daily treated with saline and the control group consisted of intact animals without any prenatal intervention.

Latencies of withdrawal reflexes of hind limbs and the tail on thermal nociceptive stimuli (Plantar Test, Ugo Basile, Comero, Italy) were repeatedly measured in 15-min intervals after the application of $5 \mathrm{mg} / \mathrm{kg}$ s.c. of AMPH, METH, COC, MDMA or MOR. Last measurement was performed $45 \mathrm{~min}$ after the injection. Analgesic efficacy was expressed as area under curve (AUC) calculated separately from the latencies of tailflick responses and paw withdrawal reflexes to thermal stimuli after drug injection.

In the plantar test, animals were freely moving in Plexiglas box (size 27x17x14 cm) without any restriction. Nociception was tested after five-minute adaptation, after vanishing of exploratory activity induced by the new environment. Hind paws were tested first, followed by the tail. Four repeated measurements at different places of the distal part of the tail were used. Stimulation was repeated approximately in half-minute intervals. Mean values of hind limbs and the tail were used for the analysis.

Number of defecation boluses and number of missing measurements after each drug were recorded at the end of each experimental session. The total number of missing measurements was considered a "stereotypy index".

All experiments were approved by the Committee of Animal Care and Use of the Third Faculty of Medicine, Charles University in Prague and conducted according to the guidelines of the Ethics Committee of the International Association for the Study of Pain (Zimmermann 1983).

\section{Statistical analyses}

\section{Analgesia}

The area under the curve was calculated using the trapezoidal method to provide an integral measure of pain intensity throughout the observation period. Changes in nociception after drug applications (AUC) were analyzed by two-way ANOVA (between subject variability - factors group and drug) separately for hind limbs and the tail. Where indicated, simple planned comparisons or Bonferonni test were used in the post-hoc analyses.

\section{Behavior}

Between-group differences in frequency of defecation and index of stereotypy (assessed as nonrealized measurements after drug application) as well as the effect of treatment were analyzed using nonparametric Kruskal-Wallis test and Mann-Whitney test. Spearman rank correlation analysis was used for assessment of association between analgesia and defecation. Differences were considered significant if $\mathrm{p}<0.05$. 

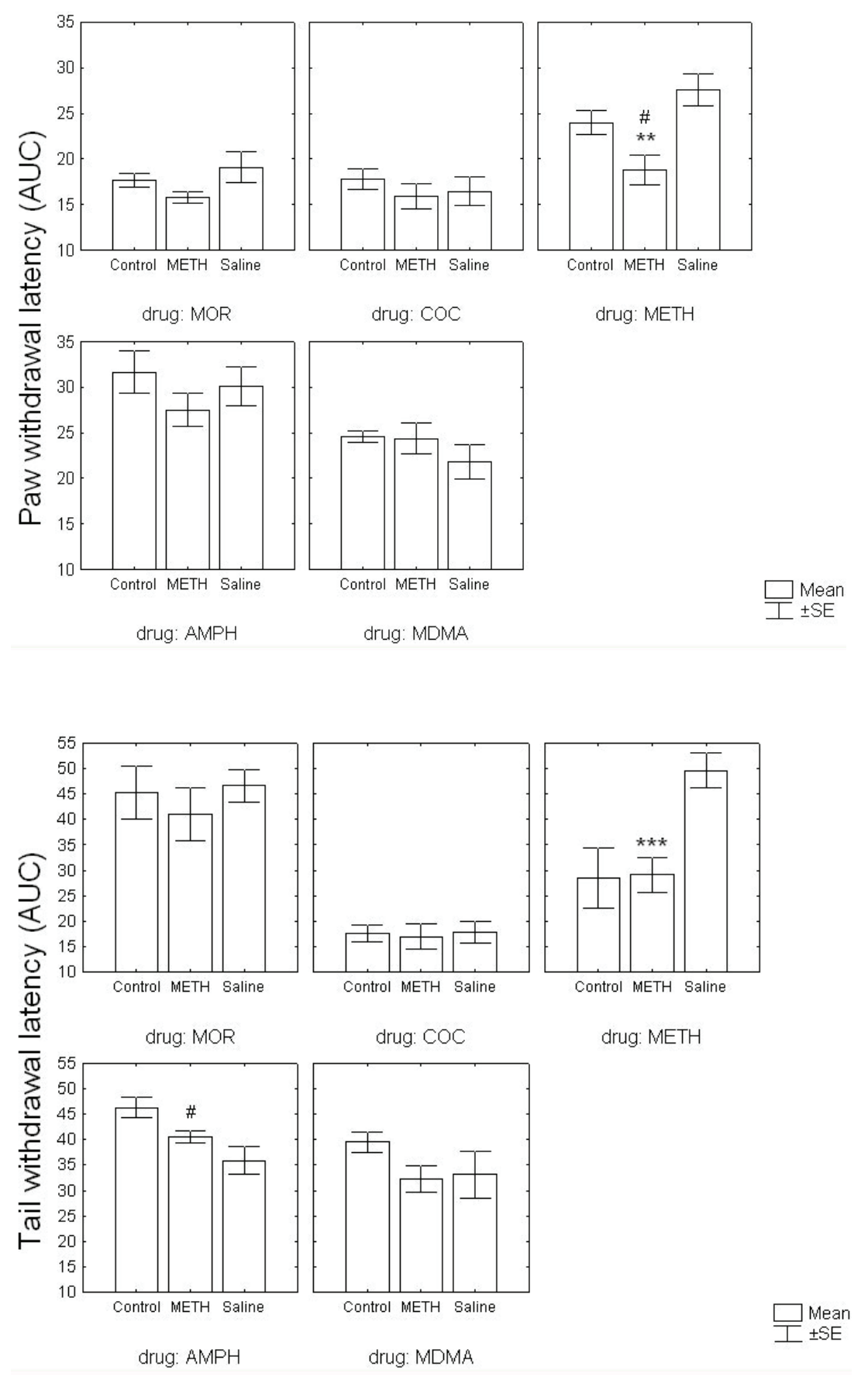

Fig. 1. Group differences in analgesia on the hind limbs after application of morphine and psychostimulants. \# $\mathrm{p}<0.05$ vs. Control; $* * p<0.01$ vs. Saline
Fig. 2. Group differences in analgesia on the tail after application of morphine and psychostimulants. \# p<0.05 vs. Control; $* * * \mathrm{p}<0.001$ vs. Saline

\section{Results}

\section{Analgesia}

On the hind limbs, results of ANOVA showed that analgesic efficacy of different drugs significantly differed $(F(4,96)=35.2, \quad \mathrm{p}<0.0001)$. AMPH induced strongest antinociceptive effect (in all comparisons $\mathrm{p}<0.001$, Bonferonni post hoc test), followed by MDMA and METH which both had similar analgesic potency but significantly higher than MOR and COC (all $\mathrm{p}<0.001$ ).

Furthermore we found significant main effect of factor group $(F(2,96)=4.47, p=0.013)$. Prenatally METH exposed rats had less analgesia in comparison with both control groups ( $p=0.044$ vs. control, $p=0.049$ vs. saline). As interaction of factors drug $\mathrm{x}$ group was non-significant $(F(8,96)=1.68, p=0.113)$, this effect was similar across all treatments but only after METH application, differences in analgesia reached statistical significances $(\mathrm{t}=2.36$, $\mathrm{p}=0.037$ vs. control, $\mathrm{t}=3.59, \mathrm{p}=0.003$ vs. saline) (Fig. 1 ).

Analgesic efficacy of different drugs on the tail was also dependent on the treatment $(\mathrm{F}(4,91)=31.38$, $\mathrm{p}<0.0001)$. MOR was the most potent drug; its effect was 
stronger than that of COC $(p<0.0001)$ METH $(p=0.019)$, MDMA ( $p=0.015)$, but did not differ from AMHP. On the other hand, no significant differences were found between AMPH, METH and MDMA, but all these psychostimulants were more potent that COC (all $\mathrm{p}<0.0001)$.

On the tail, contrary to the hind limbs, the main effect of group, was non-significant $(F(2,91)=2.58$, $\mathrm{p}=0.081$ ), however, there was significant drug $\mathrm{x}$ group interaction $(\mathrm{F}(8,91)=3.187, \mathrm{p}=0.003)$. Post hoc analyses showed that in prenatally METH treated rats, METH application induced weaker analgesia than in saline group $(\mathrm{t}=4.10, \mathrm{p}=0.001)$ and AMPH application induced weaker analgesia than in control group $(\mathrm{t}=2.48, \mathrm{p}=0.027)$ (Fig. 2).

\section{Behavior}

As MOR and COC induce no stereotypy, these drugs were excluded from further analysis. Comparison of stereotypy index in remaining three groups showed significant differences between them $(\mathrm{KW}-\mathrm{H}(2,72)=9.19$, $\mathrm{p}=0.01)$. Hyperactivity induced by MDMA was significantly higher than after AMPH $(p=0.003)$ and marginally higher than after METH ( $p=0.075)$ (Fig. 3). In addition, no group differences were found in this index $(\mathrm{KW}-\mathrm{H}(2,72)=2.50, \mathrm{p}=0.286)$.

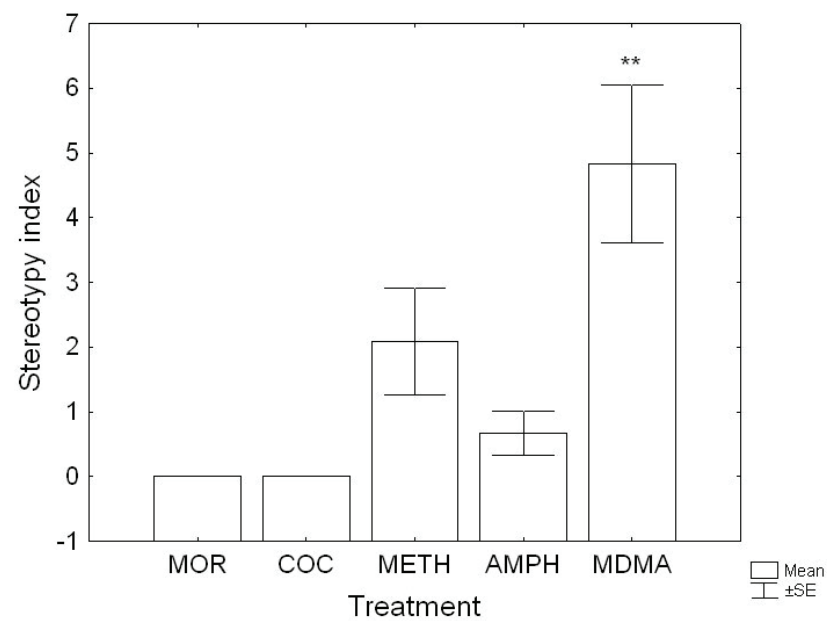

Fig. 3. Effect of morphine and psychostimulants on the stereotypy index, regardless of prenatal exposure. $* * p<0.01$ vs. AMPH

All groups, regardless of treatment, did not differ in defecation score $(\mathrm{KW}-\mathrm{H}(2,119)=1.30, \mathrm{p}=0.521)$, however, the effect of treatment was highly significant $(\mathrm{KW}-\mathrm{H}(4,119)=30.92, \mathrm{p}<0.0001)$. The highest number of defecation boluses were recorded after AMPH (in all comparisons $\mathrm{p}<0.05$, Mann-Whitney test), followed by MDMA and METH which had similar effect, significantly different both from MOR and COC (in all comparisons $\mathrm{p}<0.05$ ) (Fig. 4).

Apparent similarity between main effects of treatment on analgesia and defecation score led us to test this association in all three groups individually. Analysis reveals significant positive correlations between these two variables in all groups (control: $\mathrm{R}=0.487, \mathrm{p}=0.002$, METH: $\mathrm{R}=0.337, \mathrm{p}=0.036$, saline: $\mathrm{R}=0.527, \mathrm{p}=0.001$ ) (Fig. 5).

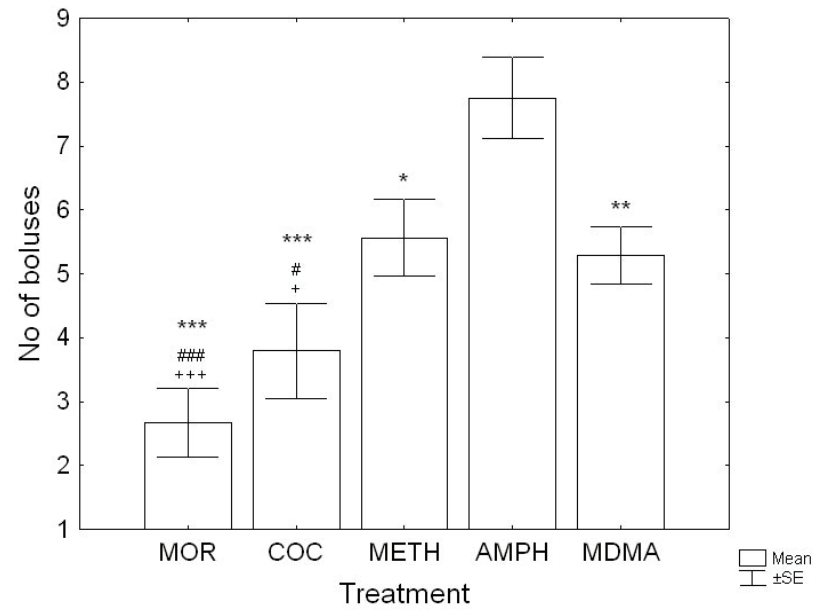

Fig. 4. Effect of morphine and psychostimulants on defecation, regardless of prenatal exposure. * $\mathrm{p}<0.05$, ** $\mathrm{p}<0.01$, $* * * \mathrm{p}<0.001$ vs. AMPH; \# $\mathrm{p}<0.05, \# \# \# \mathrm{p}<0.001$ vs. METH; $+p<0.05,+++p<0.001$ vs. MDMA

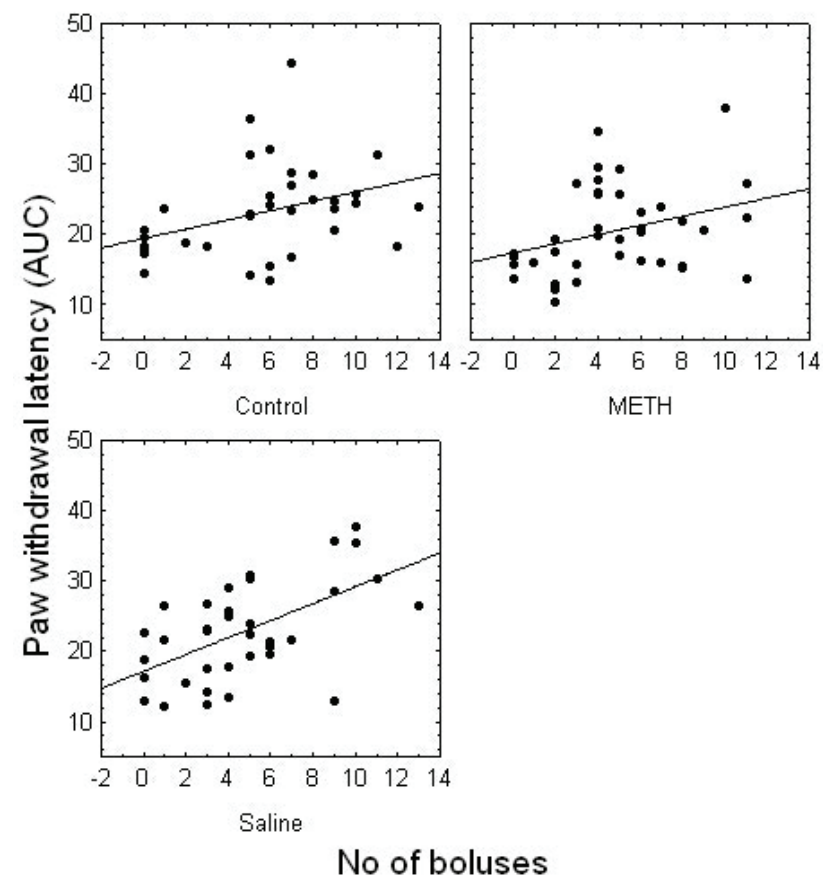

Fig. 5. Correlation between analgesia on the hind limbs and defecation score in the groups with different prenatal treatment. (Control: $R=0.487, p=0.002, M E T H: R=0.337, p=0.036$, Saline: $\mathrm{R}=0.527, \mathrm{p}=0.001$ ) 


\section{Discussion}

\section{Drug differences}

Both on hind limbs and the tail, AMPH was more potent antinociceptive drug than METH, whereas COC was practically without any effect. On the hind limbs, effect of MOR did not differ from that of COC. On the other hand, in the tail-flick test, MOR and AMPH induced the strongest analgesia.

Although psychostimulants caused similar analgesia in both parts of the body tested, the situation was different after MOR application. The greatest analgesia was observed on the tail, while on the hind limbs was almost without any effect. These results are in agreement with the study of Morgan et al. (2006) who found that morphine MOR potency varies depending on the test used to assess nociception. Thermal tests are relatively sensitive to MOR antinociception, however, the one exception was the low MOR potency on paw withdrawal to radiant heat. Paw withdrawal reflexes are under supraspinal control while the tail flick test is organized at the level of the spinal cord (Le Bars et al. 2001).

Analgesic effects of dopaminergic agonists has been demonstrated especially in models of tonic pain (formalin test), whereas in phasic pain tests (tail flick) it has been shown that AMPH and COC did not affect either the latency of pain response or, conversely, had a weak hyperalgesic effect (Altier and Stewart 1999). On the other hand, opioids, which also enhance dopaminergic transmission, have a strong analgesic effect in tests both of phasic and tonic pain. This is consistent with our observations that MOR when compared to psychostimulants had stronger analgesic effect mainly in the tail-flick test, whereas psychostimulants were more effective than morphine in the plantar test.

Dopaminergic neurons operate in two modes. Tonic dopaminergic activity indicates the level of extrasynaptic dopamine, located in normal concentrations in the extracellular space. Tonic dopamine regulates response of phasic release of dopamine to relevant stimuli from the environment. A high level of tonic dopamine weakens phasic release, while a low level of tonic dopamine facilitates phasic release (Wood 2006). As analgesic action of mesolimbic dopamine is related to phasic activity, the question arises whether the basal nociception can be associated with tonic dopamine levels. Results of Lapirot et al. (2011) suggest that tonic stimulation of D2-like receptors within the dorsal horns of the spinal cord is necessary to maintain normal nociceptive responses.

Neurons containing dopamine and opioids coexist in substantia nigra and VTA. Selective agonists for $\mu$ and $\delta$ opioid receptors increase the extracellular concentration of dopamine in the NAc and striatum when administered systemically or into the VTA or substantia nigra. This opioid-induced release of dopamine is probably caused secondarily due to inhibition of GABA interneurons and thus results in desinhibition of dopaminergic neurons (Chefer et al. 2006). Furthermore, there was a positive correlation between basal dopamine levels and the glutamate/GABA ratio in the VTA. On the other hand, opioid antagonist naloxon attenuates amphetamine-induced increases in extracellular dopamine in the terminal regions of the nigrostriatal and mesolimbic pathways in rats (Schad et al. 2002). This study also demonstrated that endogenous opioids in the $\mathrm{NAc}$ and the substantia nigra increase extracellular dopamine under the influence of AMPH but not under influence of COC. A possible mechanism consists in the different effects of these substances. COC blocks the reuptake of dopamine while AMPH increases dopamine release much more than COC. AMPH also causes a large increase in extracellular noradrenalin, so AMPH may more amplify the release of endogenous opioids.

Experimental study of Shoblock et al. (2003) has shown that METH and AMPH increase levels of dopamine in the NAc in a similar quantity contrary to the prefrontal cortex where METH was less effective than AMPH. Another difference between METH and AMPH was observed in their effect on the glutamate level. In NAc, glutamate was increased after application of AMPH but not after METH, however, in prefrontal cortex the effect was opposite; METH increased glutamate level more than AMPH.

For understanding analgesic effect of psychostimulants, it is also important to mention the fact that VTA neurons receive nociceptive information and are involved in pain modulation (Altier and Stewart 1999, Morgan and Franklin 1990). The midbrain periaqueductal gray (PAG), which plays a key role in activating descending antinociceptive system and triggering either active or passive defensive behaviors in animals (Bandler and Shipley 1994), sends excitatory afferents to dopamine cells and inhibitory afferents to GABA cells (Omelchenko and Sesack 2010) and therefore could be involved in modulating VTA responses not only to psychostimulant and opioid drugs but also to pain. 


\section{Group differences}

Analgesic efficacy of METH was lower in prenatally METH treated rats than in both control groups. This observation may reflect either weak tolerance to the same drug in adulthood or may be considered a result of long-term consequences of generally increased nociceptive sensitivity observed in these animals. Prenatal exposure to METH alters also the mechanical withdrawal threshold. The METH group rats had significantly lower tactile withdrawal values in von Frey test and higher pain scores in the late phase of pain in the formalin test than those of the control rats (Chen et al. 2010). As analgesic efficacy of other tested drugs was in all groups comparable, we can exclude the development of or cross-sensitization to drug with similar (psychostimulants and MDMA) or dissimilar mechanism of action (MOR).

\section{Body site differences}

We also showed that analgesia was increasing in rostro-caudal direction. All psychostimulant drugs, irrespective of absolute level of analgesia, had comparable antinociceptive effect if expressed relatively as tail/paw ratio (approximately 1.5 longer latencies on tail than on hind limbs during last measurement). In MOR group this ratio was nearly four. The different analgesic potencies of psychostimulants and MOR at different body sites may indicate the possible existence of a somatotopic organization of pain inhibition, which is controlled by different mechanisms.

Fang and Proudfit $(1996,1998)$ showed that morphine microinjected in the ventrolateral periaqueductal gray inhibits nociceptive responses to noxious heating of the tail by activating descending neuronal systems that are different from those that inhibit the nociceptive responses to noxious heating of the feet. Morphine produces inhibition of nociceptive tail responses that is mediated by cholinergic, serotonergic and $\alpha 2$-adrenergic receptors in the spinal cord. In contrast, two opposing effects are observed on nociceptive foot responses - facilitation of nociceptive responses mediated by $\alpha 1$ adrenoreceptors in the spinal cord and inhibition of nociceptive responses mediated by cholinergic receptors.

\section{Behavior}

MDMA induced stronger stereotypy than METH and AMPH. Unlike AMPH and METH, which have effects mediated by the release of dopamine, MDMA- induced hyperactivity is thought to be dependent upon the release of serotonin (Bankson and Cunningham 2001). This is also confirmed by the fact that neither the opiate antagonist naltrexone nor the adrenoceptor antagonist phentolamine effectively attenuated MDMA-induced analgesia. Conversely, the serotonin antagonist methysergide significantly reversed the analgesic effects of MDMA on the hot-plate test (Crisp et al. 1989).

Even though the number of fecal boluses as measure of anxiety has been relatively frequently criticized (Lister 1990), observed association between defecation and analgesia in all tested groups is rather surprising finding. More "anxious" animals developed stronger analgesia than less anxious ones. This observation supports our previous finding when data from the elevated plus maze were correlated with latencies in the plantar test where the more anxious animals had also higher latencies than less anxious ones probably due to weak stress analgesia induced by new environment (Yamamotová et al. 2007).

Particularly in animal models, it is difficult to distinguish between fear and anxiety and it is often difficult to know whether aversive nociceptive stimuli induce anxiety or physiological stress. Fear is an instant reaction to acute danger, whereas anxiety is an emotional response associated with the anticipation of a potential threat and is followed by a state of hypervigilance and somatic tension. Anxiety in humans, in contrast to fear, evokes hyperalgesia (Janssen and Arntz 1997, Rhudy and Meagher 2000). In our experiment, higher analgesia was observed together with higher "anxiety" and lower exploratory activity.

Which the neurophysiological mechanism responsible for this type of behavioral phenotype is not yet known, the role of serotonergic, as well as the noradrenergic system needs intensive study, however. Psychostimulant drugs interact with monoamine transporters and increase extracellular serotonin, dopamine and noradrenalin in the brain. Noradrenergic system has a reciprocal relationship with the serotonergic one. Activation of $\alpha 1$ adrenergic receptors potentiates anxiety and increases the release of serotonin; whereas activation of $\alpha 2$ receptors has anxiolytic effects and the amount of serotonin released is decreased (Ninan 1999).

The role of serotonin will be dependent on the type of receptors activated. Müller et al. (2007) reported that presynaptic autoreceptors (5-HT1A) mainly facilitate psychostimulant related behaviors by a limitation of serotonin response in terminal areas, whereas 
postsynaptic 5-HT1A receptors predominantly inhibit the expression of various behaviors. Serotonin acting through 5-HT2 receptors has antirewarding effect (Franklin 1998).

Concerning pain, serotonin and noradrenaline are considered important modulators of pain transmission, especially in descendent antinociceptive system. Serotonergic neurons directly suppress the dorsal horn neurons receiving nociceptive inputs from periphery (Jacobs et al. 2002, Millan 1995) or inhibit activity of pro-nociceptive "on" cells and/or activate antinociceptive "off" cells in the rostral ventromedial medulla (Mason 1999, Roychowdhury and Heinricher 1997). Similar effect of serotonin was described in the regulation of the neural substrates of fear in the dorsal periaqueductal gray (Brandao et al. 2008).

\section{Conclusion}

Although psychostimulants and MOR share common feature of increasing extracellular concentration of dopamine in nucleus accumbens (either directly or indirectly), pharmacodynamics and pharmacokinetics should also be taken in account for interpretation of their different antinociceptive potency. From the above we can conclude that analgesia induced by psychostimulants is caused not only by dopamine itself, but a combination of both opioid and dopaminergic systems contributes to this type of analgesia.

The clinical aspect of present study is aimed at psychostimulant drugs as candidates for adjuvant analgesic treatment. Psychostimulants were described to evoke analgesia and antinociception in animal models of both acute (tail-flick test, hot-plate test) and tonic pain (formalin test) (Altier and Stewart 1993, Morgan and Franklin 1990). The other studies showed potentiation of opioid analgesia by psychostimulants (Dalal and Melzack 1998a). Further, psychostimulants reduce sedation and improve cognitive functions allowing using higher doses of opioids in patients with chronic pain (Dalal and Melzack 1998b). Our future research will be oriented on combination of morphine with methamphetamine.

\section{Conflict of Interest}

There is no conflict of interest.

\section{Acknowledgements}

This study was supported by grant GA 305/09/0126 from Grant Agency of the Czech Republic, project CSM 110 from Ministry of Education, Youth and Sports and projects 264706/SVV/2012 and PRVOUK P34 from Charles University in Prague.

\section{References}

ALTIER N, STEWART J: The role of dopamine in the nucleus accumbens in analgesia. Life Sci 65: 2269-2287, 1999.

BANDLER R, SHIPLEY MT: Columnar organization in the midbrain periaqueductal gray: modules for emotional expression? Trends Neurosci 17: 379-389, 1994.

BANKSON MG, CUNNINGHAM KA: 3,4-methylenedioxymethamphetamine (MDMA) as a unique model of serotonin receptor function and serotonin-dopamine interactions. J Pharmacol Exp Ther 297: 846-852, 2001.

BECERRA L, BREITER HC, WISE R, GONZALEZ RG, BORSOOK D: Reward circuitry activation by noxious thermal stimuli. Neuron 32: 927-946, 2001.

BORSOOK D, BECERRA L, CARLEZON WA Jr, SHAW M, RENSHAW P, ELMAN I, LEVINE J: Reward-aversion circuitry in analgesia and pain: implications for psychiatric disorders. Eur J Pain 11: 7-20, 2007.

BRANDAO ML, ZANOVELI JM, RUIZ-MARTINEZ RC, OLIVEIRA LC, LANDEIRA-FERNANDEZ J: Different patterns of freezing behavior organized in the periaqueductal gray of rats: association with different types of anxiety. Behav Brain Res 188: 1-13, 2008.

BUBENIKOVA-VALESOVA V, KACER P, SYSLOVA K, RAMBOUSEK L, JANOVSKY M, SCHUTOVA B, HRUBA L, SLAMBEROVA R: Prenatal methamphetamine exposure affects the mesolimbic dopaminergic system and behavior in adult offspring. Int J Dev Neurosci 27: 525-530, 2009.

CHEFER VI, DENOROY L, ZAPATA A, SHIPPENBERG TS: Mu opioid receptor modulation of somatodendritic dopamine overflow: GABAergic and glutamatergic mechanisms. Eur J Neurosci 30: 272-278, 2009.

CHEN JY, YEH GC, TAO PL, KUO CT, CHEN KB, WEN YR: Prenatal exposure to methamphetamine alters the mechanical withdrawal threshold and tonic hyperalgesia in the offspring. Neurotoxicology 31: 432-438, 2010. 
CRISP T, STALINSKY JL, BOJA JW, SCHECHTER MD: The antinociceptive effects of 3,4methylenedioxymethamphetamine (MDMA) in the rat. Pharmacol Biochem Behav 34: 497-501, 1989.

DALAL S, MELZACK R: Psychostimulant drugs potentiate morphine analgesia in the formalin test. J Pain Symptom Manage 16: 230-239, 1998a.

DALAL S, MELZACK R: Potentiation of opioid analgesia by psychostimulant drugs: a review. J Pain Symptom Manage 16: 245-253, $1998 \mathrm{~b}$.

FANG F, PROUDFIT HK: Spinal cholinergic and monoamine receptors mediate the antinociceptive effect of morphine microinjected in the periaqueductal gray on the rat tail but not the feet. Brain Res 722: 95-108, 1996.

FANG F, PROUDFIT HK: Antinociception produced by microinjection of morphine in the periaqueductal gray is enhanced in the foot, but not the tail, by intrathecal injection of $\alpha 1$-adrenoreceptor antagonists. Brain Res $\mathbf{7 9 0}$ : 14-24, 1998.

FRANKLIN KBJ: Analgesia and abuse potential: an accidental association or a common substrate? Pharmacol Biochem Behav 59: 993-1002, 1998.

JACOBS BL, MARTÍN-CORA FJ, FORNAL CS: Activity of medullary serotonergic neurons in freely moving animals. Brain Res Rev 10: 45-52, 2002.

JANSSEN SA, ARNTZ A: No evidence for opioid-mediated analgesia induced by phobic fear. Behav Res Ther 35: 823-830, 1997.

JOHNSON SW, NORTH RA: Opioids excite dopamine neurons by hyperpolarization of local interneurons. J Neurosci 12: 483-488, 1992.

KOOB GF: Drugs of abuse: anatomy, pharmacology and function of reward pathways. Trends Pharmacol Sci 13: $177-$ $184,1992$.

LAPIROT O, MELIN C, MODOLO A, NICOLAS C, MESSAOUDI Y, MONCONDUIT L, ARTOLA A, LUCCARINI P, DALLEL R: Tonic and phasic descending dopaminergic controls of nociceptive transmission in the medullary dorsal horn. Pain 152: 1821-1831, 2011.

LE BARS D, GOZARIU M, CADDEN SW: Animal models of nociception. Pharmacol Rev 53: 597-652, 2001.

LEKNES S, TRACEY I: A common neurobiology for pain and pleasure. Nat Rev Neurosci 9: 314-320, 2008.

LISTER RG: Ethologically-based animal models of anxiety disorders. Pharmacol Ther 46: 321-340, 1990.

MASON P: Central mechanisms of pain modulation. Curr Opin Neurobiol 9: 436-441, 1999.

MILLAN MJ: Serotonin (5-HT) and pain: a reappraisal of its role in the light of receptor multiplicity. Semin Neurosci 7: 409-419, 1995.

MORGAN MJ, FRANKLIN KBJ: 6-hydroxydopamine lesions of the ventral tegmentum abolish D-amphetamine and morphine analgesia in formalin test but not in the tail flick test. Brain Res 519: 144-149, 1990.

MORGAN MJ, FRANKLIN KBJ: Dopamine receptors subtypes and formalin test analgesia. Pharmacol Biochem Behav 40: 317-322, 1991.

MORGAN MM, FOSSUM EN, STALDING BM, KING MM: Morphine antinociceptive potency on chemical, mechanical, and thermal nociceptive tests in rats. J Pain 7: 358-366, 2006.

MÜLLER CP, CAREY RJ, HUSTON JP, DE SOUZA SILVA MA: Serotonin and psychostimulant addiction: focus on 5-HT1A-receptors. Prog Neurobiol 81: 133-178, 2007.

NINAN PT: The functional anatomy, neurochemistry, and pharmacology of anxiety. J Clin Psychiatry 60 (Suppl 22): 12-17, 1999.

OHMORI T, ABEKAWA T, KOYAMA T: The role of glutamate in behavioral and neurotoxic effects of methamphetamine. Neurochem Int 29: 301-307, 1996.

OMELCHENKO N, SESACK SR: Periaqueductal gray afferents synapse onto dopamine and GABA neurons in the rat ventral tegmental area. J Neurosci Res 88: 981-991, 2010.

RHUDY JL, MEAGHER W: Fear and anxiety: divergent effects on human pain thresholds. Pain 84: 65-75. 2000.

ROTHMAN RB, BAUMANN MH, DERSCH CM, ROMERO DV, RICE KC, CAROLL FI, PARTILLA JS: Amphetamine-type central nervous system stimulants release norepinephrine more potently than they release dopamine and serotonin. Synapse 39: 32-41, 2001.

ROTHMAN RB, BAUMANN MH: Monoamine transporters and psychostimulant drugs. Eur J Pharmacol 479: 23-40, 2003. 
ROYCHOWDHURY SM, HEINRICHER MM: Effects of iontophoretically applied serotonin on three classes of physiologically characterized putative pain modulating neurons in the rostral ventromedial medulla of lightly anesthetized rats. Neurosci Lett 226: 136-138, 1997.

SCHAD C, JUSTICE JB, HOLTZMAN SG: Endogenous opioids in dopaminergic cell body regions modulate amphetamine-induced increases in extracellular dopamine levels in the terminal regions. J Pharmacol Exp Ther 300: 932-938, 2002.

SHOBLOCK JR, SULLIVAN EB, MAISONNEUVE IM, GLICK SD: Neurochemical and behavioral differences between d-methamphetamine and d-amphetamine in rats. Psychopharmacology 165: 359-369, 2003.

WOOD PB: Mesolimbic dopaminergic mechanisms and pain control. Pain 120: 230-234, 2006.

YAMAMOTOVÁ A, POMETLOVÁ M, HARMATHA J, RAŠKOVÁ H, ROKYTA R: The selective effect of Nferuloylserotonins isolated from Leuzea carthamoides on nociception and anxiety in rats. J Ethnopharmacology 112: 368-374, 2007.

YAMAMOTOVÁ A, HRUBÁ L, SCHUTOVÁ B, ROKYTA R, ŠLAMBEROVÁ R: Perinatal effect of methamphetamine on nociception in adult Wistar rats. Int J Dev Neurosci 29: 85-92, 2011.

ZIMMERMANN M: Ethical guidelines for investigations of experimental pain in conscious animals. Pain 16: 109-110, 1983. 